\title{
Records of giant squid in the north-eastern Atlantic, and two records of male Architeuthis sp. off the Iberian Peninsula
}

\author{
A. Guerra* ${ }^{\ddagger}$, A.F. González*, E.G. Dawe ${ }^{\dagger}$ and F. Rocha* \\ *Instituto de Investigaciones Marinas (CSIC), ECOBIOMAR, Eduardo Cabello 6, 36208 Vigo, Spain. 'Science Oceans and \\ Environment Branch, Department of Fisheries and Oceans, PO Box 5667, St John's, Canada, AlC 5X1. \\ ${ }^{\ddagger}$ Corresponding author, e-mail: brcl@iim.csic.es
}

\begin{abstract}
A review of the verified reports to date of Architeuthis spp. showed that 33.9\% (115 specimens) of worldwide reports were derived from the north-eastern Atlantic. The sex of each specimen, nature of the report, as well as the season and area of collection are presented. Biological data are presented on the two first males of Architeuthis sp. captured off the Iberian Peninsula. The first male (42 kg and $98 \mathrm{~cm}$ mantle length) was caught at $43^{\circ} 54.26^{\prime} \mathrm{N} 5^{\circ} 29.38^{\prime} \mathrm{W}$ by pair trawlers on 13 September 2002. Spermatophores ranged from 11 to $20 \mathrm{~cm}$ in length. The peculiar observation of other spermatophores embedded in the skin near the proximal part of the ventral, ventro-lateral and dorso-lateral arms is discussed. The second male $(66 \mathrm{~kg}$ and $122 \mathrm{~cm}$ mantle length) was found floating on the surface off Gijón on 16 September 2003. Although mature, no spermatophores embedded in the skin were observed. A comparison was undertaken of several morphometric measurements between these two males and five other north-eastern Atlantic males from which data were available.
\end{abstract}

\section{INTRODUCTION}

To date, there is a remarkable lack of information regarding the giant squid Architeuthis spp., especially for males. Teuthologists have not been able to resolve the species composition of this genus. Historically, 21 nominal species have been assigned to this genus (Sweeney \& Roper, 2001). However, based strictly on morphological characters related to the head width and the fin shape, these 21 nominal species could be reduced considerably. Furthermore, the material obtained to date, primarily from dead animals or those captured by nets, is from broadly-dispersed locations and generally in such poor condition as to preclude acquisition of precise morphological data.

Sweeney \& Roper (2001) noted that among the animals recorded from the North Atlantic, there have only been 17 males (eight from the north-west and nine from the northeast) and only five of these provided detailed information on morphology and some biological characteristics (Knudsen, 1957; Kjennerud, 1958; Aldrich, 1992; Lordan et al., 1998).

We review the distribution of giant squid location sites in the north-eastern Atlantic, report the capture of the two first male specimens of Architeuthis in waters off the Spanish Iberian Peninsula, and compare their morphological characteristics with those of other males previously found in the north-eastern Atlantic.

\section{MATERIALS AND METHODS}

The pair trawlers 'Helena María' and 'Bautista Pino' captured a male of Architeuthis sp. on 13 September 2002 in the proximity of Pozo de la Vaca $\left(43^{\circ} 54.26^{\prime} \mathrm{N}\right.$ $\left.5^{\circ} 29.38^{\prime} \mathrm{W}\right)$ at a depth of about $450-475 \mathrm{~m}$. A second male was found moribund and floating at the surface off Gijón $\left(43^{\circ} 53.23^{\prime} \mathrm{N} 5^{\circ} 32.15^{\prime} \mathrm{W}\right)$ on 16 October 2003. These animals were maintained frozen and delivered to Aula del Mar (CEPESMA) in Luarca (Asturias, Spain), where they were studied after being defrosted at room temperature. Morphometric data were collected in the laboratory according to Roper \& Voss (1983). Data from these two males, the only males to date from waters off the Iberian Peninsula, were compared with those of other giant squids reported from the north-eastern Atlantic (Sweeney \& Roper 2001; González et al., 2002; unpublished data).

\section{RESULTS}

Table 1 shows the records of Architetuhis spp. in the north-eastern Atlantic from published reports updated to October 2003. Among the 115 specimens of giant squid reported in the north-eastern Atlantic, only seven were captured alive, five of them in northern Spanish waters where trawlers targeted blue whiting mainly during summer and autumn. Although sex was undetermined for most of the specimens from the north-eastern Atlantic $(65.2 \%)$, an unequal sex ratio, strongly favouring females (3:1), was evident among those specimens of known sex.

Figure 1 illustrates the dissection of the first (September 2002) male. The size of the fresh animal was $42 \mathrm{~kg}$ in total body weight (BW), $98 \mathrm{~cm}$ in mantle length (ML) and $600 \mathrm{~cm}$ in total length (TL). The penis length was $88 \mathrm{~cm}$ and it protruded $20 \mathrm{~cm}$ outside the mantle (Figure 1). We found several spermatophores within the Needham's sac, ranging $11-20 \mathrm{~cm}$ in length, indicating that the animal was functionally mature. Other spermatophores were observed embedded in the skin near the proximal part of the ventral, ventro-lateral and dorso-lateral arms 
Table 1 Records of Architeuthis in the north-eastern Atlantic since 1545. (v) Specimens captured alive.

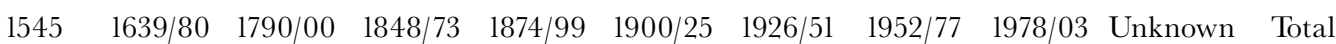

\section{Country}

Sweden

Iceland

Ireland

Norway

Denmark

Scotland

Canary Islands

Azores

England

France (Bay of Biscay)

Madeira

Galicia (Spain)

Asturias (Spain)

Huelva (Spain)

Portugal

Germany

Season

Spring

Summer

Autumn

Winter

Unknown

\section{1}

ex

Male

Female

Sex not determined

Sampling procedure

Stranding

Capture

Floating on the surface

From predators

Unknown

$\begin{array}{lllll}1639 / 80 & 1790 / 00 & 1848 / 73 & 1874 / 99 & 1900 / 25\end{array}$

$1952 / 77$


Table 2. Male records of Architeuthis with morphometric data in the north-eastern Atlantic.

\begin{tabular}{|c|c|c|c|c|c|c|c|c|c|c|}
\hline & D (1957) & N (1958) & IR (1998) & IR (1998) & IR (1998) & $\mathrm{AS}(2002)$ & $\mathrm{AS}(2003)$ & I & Mean & $\mathrm{SD}$ \\
\hline ML & 101 & 100 & 102.8 & 97.5 & 108.4 & 100 & 122 & MLI & 16.8 & 0.4 \\
\hline BW & - & 48 & 26.9 & 22.45 & 26.5 & 43 & 66 & & & \\
\hline Mat & Mature & Mature & Mature & Mature & Mature & Mature & Mature & & & \\
\hline VML & 94 & 87 & & & & 92 & 116 & & & \\
\hline HL & 27.5 & $30-32$ & 27.5 & 27 & 28.8 & 27 & 28.9 & HLI & 27.6 & 1.6 \\
\hline HW & & 25 & 13.5 & 13.7 & 14.4 & 28 & - & & & \\
\hline ALI & 80 & $126+$ & 87 & - & - & - & - & & & \\
\hline ALII & & $143++$ & - & - & - & - & - & & & \\
\hline ALIII & & $126+$ & 105.4 & - & - & - & - & & & \\
\hline ALIV & $147 / 153$ & 164 & $151.2 / 146.5$ & - & 111.1 & 176 & - & & & \\
\hline LAL & 153 & 164 & 151.2 & & 111.1 & 176 & - & LALI & 146.4 & 21.3 \\
\hline HeL & $\begin{array}{l}\text { IV pair } \\
(9 / 13)\end{array}$ & IV pair & No obs. & No obs. & No obs. & $\begin{array}{l}\text { IV pair } \\
(4.5)\end{array}$ & - & & & \\
\hline ACI & & 16 & & & & 15.4 & 16.2 & & & \\
\hline ACII & & 20 & & & & 19.7 & 20.4 & & & \\
\hline ACIII & & 22 & & & & 21.6 & 21.2 & & & \\
\hline ACIV & & 22 & & & & $20+$ & 25.1 & & & \\
\hline $\mathrm{AF}$ & & 4.3 .2 .1 & & & & 4.3 .2 .1 & 4.3.2.1 & & & \\
\hline $\mathrm{TeL}$ & 490 & - & 455.5 & 482.3 & - & $420 / 470$ & - & TeLI & 462.6 & 30.8 \\
\hline ToL & & - & 597 & 595 & - & 600 & - & & & \\
\hline $\mathrm{TC}$ & & - & 50.4 & 50.0 & - & 51 & - & TCI & 11.1 & 0.7 \\
\hline $\mathrm{DC}$ & & - & 15.8 & 17.2 & - & 15 & - & DCI & 31.7 & 2.5 \\
\hline $\mathrm{MaL}$ & & - & 25.2 & $25.2 / 23.6$ & - & 29 & - & MaLI & 51.1 & 4.1 \\
\hline $\mathrm{CaL}$ & & - & 9.4 & $7.7 / 9.2$ & - & 7.9 & - & CaLI & 16.9 & 1.8 \\
\hline $\mathrm{FL}$ & & 28-32 & 39 & 35.6 & 36.8 & 30 & 42 & FLI & 33.8 & 3.3 \\
\hline FW & & $13(26)$ & $14.9(29.8)$ & $13.3(26.6)$ & $13.2(26.4)$ & $14(28)$ & - & FWI & 26.9 & 1.8 \\
\hline $\mathrm{TaL}$ & & 10 & & & & 8 & - & & & \\
\hline $\mathrm{BC}$ & & 80 & & & & 76 & 82 & & & \\
\hline MW & & & 37.9 & 33.5 & 33.5 & 33 & 38 & & & \\
\hline ED & & & 8 & 9.5 & 9.6 & $8 / 10$ & $9.5 / 10.3$ & EDI & 8.7 & 0.9 \\
\hline FuL & & 14 & & & & 17 & 17 & & & \\
\hline $\mathrm{FuO}$ & & 7 & & & & 5.5 & 7.6 & & & \\
\hline FuCL & & 12 & & & & 12 & 14.5 & & & \\
\hline FuCW & & 2.5 & & & & 3 & 3.6 & & & \\
\hline PL & 78 & 92 & 55.5 & 57.4 & 70.2 & 88 & 96.5 & PLI & 73.3 & 14.7 \\
\hline SSL & 15.5 & & & & & 30 & 32.9 & & & \\
\hline SoA & No obs. & Yes & No obs. & No obs. & No obs. & Yes & No obs. & & & \\
\hline SL & $11.0-18.0$ & & $12.5-15.0$ & $12.0-14.0$ & $13.5-15.5$ & $11.0-20.0$ & $12.3-20.1$ & SLI & $11.5-16.3$ & $1.0-2.3$ \\
\hline LRL & & 1.2 & 1.09 & 1.27 & 1.33 & 1.2 & 1.34 & LRLI & 1.18 & 0.09 \\
\hline URL & & 1.5 & 1.25 & 1.2 & 1.0 & 1.0 & 1.2 & URLI & 1.14 & 0.22 \\
\hline SInc & & & 294 & 375 & 422 & - & - & & & \\
\hline $\mathrm{G}(\mathrm{W})$ & & & 4.25 & 3.29 & 2.96 & - & - & & & \\
\hline
\end{tabular}

Origin: D, Denmark (Knudsen, 1957); N, Norway (Kjennerud, 1958); IR, Ireland (Lordan et al., 1998); AS, Asturias, Spain. Characters: ML, dorsal mantle length; BW, body weight; Mat, maturity stage; VML, ventral mantle length; head length; HL, hectocotylized part of arm; HW, head width; ALI, ALII, ALIII and ALIV, arm length; LAL, longest arm length; HeL, hectocotylus part; ACI ACII, AGIII and AGIV, arm circumference; AF, arm formulae, TeL, tentacle length; ToL, total length; TC, tentacular club length; DC, dactylus club length; MaL, manus length; CaL, carpus length, FL, fin length; FW, fin width only one fin, both fins between brackets; TaL, tail length; BC, body circumference; MW, max mantle width; ED, eye diameter; FuL, funnel length; FuO, funnel opening diameter; FuCL, funnel cartilage length; FuCW, funnel cartilage width; PL, penis length; SSL, spermatophore sac length; SoA, spermatophores on arms; SL, spermatophore length; LRL, lower beak rostral length; URL upper beak rostral length; Sinc, number of statoliths increments; $\mathrm{G}(\mathrm{W})$, daily growth rate (\%). Indices: MLI: mantle length index=ML/TL*100; HLI: head length index $=\mathrm{HL} / \mathrm{ML} * 100$; TELI: tentacle length index $=\mathrm{TeL} / \mathrm{ML} * 100$; TCI: tentacular club index $=$ TC/TeL*100; DCI: dactylus club index =DC/CL*100; MaLI: manus length index=MaL/CL*100; CaLI: carpus length index=CaL/CL*100; FLI: fin length index $=\mathrm{FL} / \mathrm{ML} * 100$; LALI: longest arm length index $=\mathrm{LAL} / \mathrm{ML} * 100$; FWI: fin width index $=\mathrm{FL} / \mathrm{ML} * 100$ (both fins); PLI: penis length index $=\mathrm{PL} / \mathrm{ML} * 100$; EDI: eye diameter index $=\mathrm{ED} / \mathrm{ML} * 100$; SLI: spermatophore length index $=\mathrm{SL} / \mathrm{ML} * 100$; LRLI: lower rostral length index $=\mathrm{LRL} / \mathrm{ML} * 100$; URLI: upper rostral length index $=\mathrm{URL} / \mathrm{ML} * 100 ; \mathrm{S}$ Inc: statolith increments; $\mathrm{G}(\mathrm{W})$ : daily growth rate $(\%)$. Measures in $\mathrm{cm}$ or $\mathrm{Kg}$. $\mathrm{SD}=$ standard deviation.

(Figure 2). The stomach was completely empty. The second male, also mature, was $66 \mathrm{~kg}$ in BW and $122 \mathrm{~cm} \mathrm{ML}$. It was not possible to estimate TL because both tentacles were missing. The penis length was $96.5 \mathrm{~cm}$ and it protruded $23 \mathrm{~cm}$ outside the mantle. There were no spermatophores embedded in the skin. Both males were preserved and are stored in the collection of Aula del Mar. The records of male Architeuthis from the 


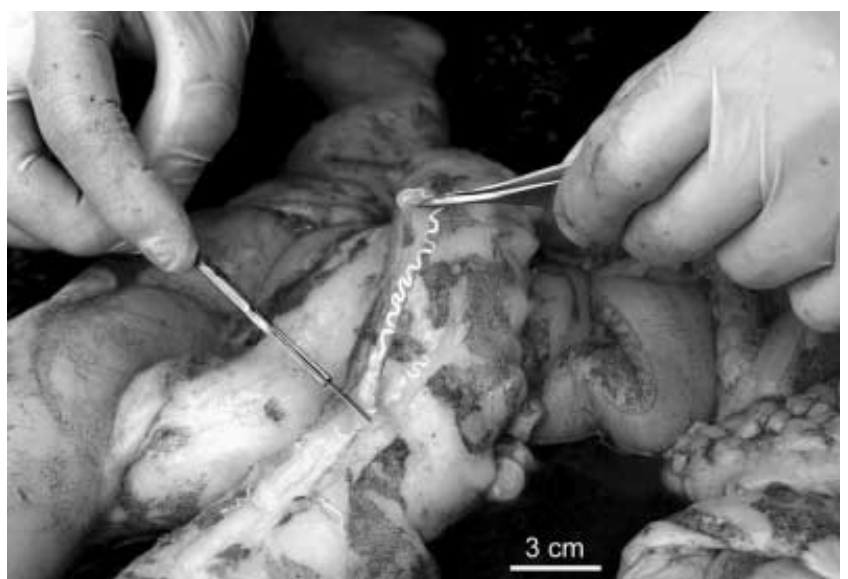

Figure 2. Spermatophores were observed embedded in the skin nearby the proximal part of the ventral, ventro-lateral and dorso-lateral arms of the male of Architeuthis caught at $43^{\circ} 54.26^{\prime} \mathrm{N} 5^{\circ} 29.38^{\prime} \mathrm{W}$.

north-eastern Atlantic, with morphological data and mean and standard deviation of the morphometric indices are summarized in Table 2.

For all males compared the total length could be partitioned among the mantle $(16.8 \%)$, the head $(4.5 \%)$ and the tentacles $(78.3 \%)$. The arms represented $24.8 \%$ of the total length. The width of the fins represented $26.9 \%$ of the mantle length. The mean eye diameter was $8.7 \%$ of the mantle length, but was highly variable. The manus, dactilus and carpus represented $51 \%, 31.7 \%$ and $16.9 \%$, respectively of the tentacular club.

\section{DISCUSSION}

The north-east Atlantic records of Architeuthis spp. represent $33.9 \%$ of the animals found worldwide. Most $(92.5 \%)$ of the animals reported from Norway were found between 1874 and 1977, being almost absent afterwards. This drastic reduction cannot be explained by a reduction in observation effort because the giant squid has received increased attention during recent years. This decrease in sightings could be related to a reduction in the frequency of oceanographic events that cause strandings. The oxygen-carrying capacity of haemocyanin in the blood system of giant squid is lower than that of other pelagic squid. Furthermore, from blood samples obtained from a giant squid captured alive in Bergen, Brix (1983) found more than a fourfold decrease in $\mathrm{O}_{2}$ affinity when temperature increased from 6.4 to $15^{\circ} \mathrm{C}$, strongly suggesting that giant squid may suffocate from arterial desaturation when ambient temperature increases. This seems to be a plausible explanation for the appearance of moribund or dead animals, floating at the surface or stranded on the shores of several European countries, where giant squid could interact with tropical water masses. It is likely that such interactions occasionally occur during some years in the North Atlantic, as a result of the eastward intensification of current flow in the Gulf Stream affecting the Irminger, Norwegian and Canary warm currents (Thurman, 1993).

It is very difficult to find a realistic explanation for the predominance of females because virtually nothing is known with respect to the life history and demography of
Architeuthis spp. This unbalanced sex ratio could represent a real predominance of females within the natural population, which seems unlikely, or it could reflect higher vulnerability of females than males to capture or stranding. Such higher vulnerability could be related to spatial segregation of the sexes. Alternatively, that most sightings were in autumn suggests that some seasonal event could be related to the preponderance of females. It is possible, for example, that sexual maturation is much more demanding of somatic resources in females than in males resulting in poorer condition and higher susceptibility of females than males to stress. However, this seems to be an unlikely explanation, as most of the females recorded from the north-east Atlantic were sexually immature or maturing, whereas the few males observed were all mature. There have only been six males of Architeuthis spp. reported since 1952 in the north-eastern Atlantic (Table 1). All of these males were functionally mature, with two of the eight (Denmark in 1957 and Asturias in 2002) having spermatophores embedded in the skin of several arms and the mantle. The presence of spermatophores in the skin could come from other males or from accidental self-implantation when the animal was attempting to impregnate a female. The latter seems to be the more plausible explanation because males of this species, being much smaller than females, possess a disproportionately large penis (Figure 1), which allows them to inject the spermatophores under high pressure. Moreover, the great length and flexibility of this organ probably results in delivery of sperm packages in several parts of their own mantle or arms, as well as the arms of a mating female; head-to-head is one of the most common mating positions in teuthoid cephalopods.

Only one mated female of Architeuthis (probably A. sanctipauli) has been reported to date (Norman \& Lu, 1997). That female also had spermatophores embedded within the skin of the two ventral arms, as Knudsen (1957) reported and as we also described in two males.

Males of several species may use their mandibles, tentacular hooks and/or arms to produce these wounds in the skin of arms and/or the mantle of females within which they then deposit their spermatophores (Nesis, 1987). Generally, in these species, the male has a long and muscular penis, which would be adaptive for inserting spermatophores into such wounds. However, these wounds have not been observed in the arms or mantle of Architeuthis spp. Therefore, the mechanism of sperm introduction to females of this species, while highly specialized, remains unknown.

The males of Architeuthis spp. studied to date were functionally mature at sizes ranging from 97.5 to $122 \mathrm{~cm} \mathrm{ML}$ and from 22.5 to $66 \mathrm{~kg}$ BW (Table 2). Our comparisons revealed morphological differences among males, (Table 2), most remarkably that males of similar mantle length showed relative penis lengths ranging from 54\% to $64.7 \%$ of $\mathrm{ML}$ in the Irish specimens and from $77 \%$ to $92 \%$ of ML in the other specimens. These, and other, measurements and indices should be interpreted with caution, however, because the specimens were preserved under various conditions and for variable periods of time. Furthermore, it is also likely that variable body weight is in part due to loss of body parts (e.g. arms) in some specimens. As noted by Lordan et al. (1998), some 
morphological differences they found may be attributable to damage at capture or to the general plasticity of cephalopod tissue. However, differences in beak morphometry and gill lamellae counts suggest that two different species may inhabit the North Atlantic. In order to resolve species composition of Architetuthis spp. in this area, and throughout the world's oceans, it would be necessary to undertake genetic analysis to determine whether morphometric and meristic differences reflect ecotypes or true species.

We thank the skippers of the pair trawlers 'Helena María' and 'Bautista Pino'. We also thank Mr Luis Laria for his helpful assistance and Dr Oscar Soriano and all members of Transglobe Films for their technical assistance. Mr Eloy Alonso provided the photographs.

\section{REFERENCES}

Aldrich, F.A., 1992. Some aspects of the systematics and biology of squid of the genus Architeuthis based on a study of specimens from Newfoundland waters. Bulletin of Marine Science, 49, 457-481.

Brix, O., 1983. Giant squids may die when exposed to warm water currents. Nature, London, 303, 422-423.

González, A.F., Guerra, A., Rocha, F. \& Gracia, J., 2002. Recent findings of the giant squid Architeuthis in northern Spanish waters. Fournal of the Marine Biological Association of the United Kingdom, 82, 859-861.
Kjennerud, J., 1958. Description of a giant squid, Architeuthis, stranded on the west coast of Norway. Universitet i Begen Arbok 1958. Naturvitenkapelig Rekke, 9, 1-14.

Knudsen, J., 1957. Some observations on a mature male specimen of Architeuthis from Danish waters. Proceedings of the Malacological Society of London, 32, 189-198.

Lordan, G., Collins, M.A. \& Perales-Raya, G., 1998. Observations on morphology, age and diet of three Architeuthis caught off the west coast of Ireland in 1995. Fournal of the Marine Biological Association of the United Kingdom, 78, 903-917.

Nesis, K.N., 1987. Cephalopods of the world. New Jersey: T.F.H. Publications.

Norman, M.D. \& Lu, G.C., 1997. Sex in giant squid. Nature, London, 389, 683-684.

Roper, G.F.E. \& Voss, G.L., 1983. Guidelines for taxonomic descriptions of cephalopod species. Memoirs of the National Museum of Victoria, 44, 49-64.

Sweeney, M.J. \& Roper, C.F.E., 2001. Records of Architeuthis specimens from published reports. National Museum of Natural History. Smithsonian Institution. http://www.mnh.si.edu/ cephs/archirec.pdf

Thurman, H.V., 1993. Essentials of oceanography. New York: Macmillan Publishing Company.

Submitted 25 September 2003. Accepted 18 February 2004. 